\title{
HELIOS, a nadir-looking sea ice monitoring camera
}

\author{
Thomas Krumpen $^{\text {a,* }}{ }^{\text {, Christian Haas }}{ }^{\text {b }}$, Stefan Hendricks ${ }^{\text {a }}$, Jens A. Hölemann ${ }^{\text {, }}$, \\ Dirk Kalmbach ${ }^{\text {a }}$, Rüdiger Gerdes ${ }^{\text {a }}$ \\ a Alfred Wegener Institute, Dept. of Sea Ice Physics, Busse Str. 24, 27570 Bremerhaven, Germany \\ ${ }^{\mathrm{b}}$ University of Alberta, Dept. of Earth \& Atmospheric Sciences, Edmonton, Alberta, Canada \\ ${ }^{c}$ Alfred-Wegener-Institute, Dept. of Observational Oceanography, Am Handelshafen 12, 27570 Bremerhaven, Germany
}

\section{A R T I C L E I N F O}

Article history:

Received 9 August 2010

Accepted 17 November 2010

\section{Keywords:}

Sea ice

Aerial photography

Survey

Photogrammetry

Digital camera

Mapping

\begin{abstract}
A B S T R A C T
We present the prototype of a simplified photogrammetric system (HELicopter-borne Ice Observation System, HELIOS) and demonstrate how it can be used to document ground-based and airborne sea ice surveys. The aerial unit consists of a nadir-looking digital camera mounted on a gimbal, a GPS receiver and a computer. It is of low-cost and weight and is designed such that it withstands low temperatures, operates autonomously and fits to any standard helicopter skid. The accuracy of the georeferenced photographs is about $\pm 15 \mathrm{~m}$ for a flight height of $85 \mathrm{~m}$, flight speed of $130 \mathrm{~km} / \mathrm{h}$ and a GPS sampling rate of $4 \mathrm{~Hz}$. Systematic errors arise from the GPS-based determination of the camera position, the pointing accuracy of the gimbal, and the camera alignment in flight direction. Because most sea ice mapping projects require lesser accuracies than conventional mapping standards (e.g. $\leq 0.5 \mathrm{~m}$ for a map scale of $1: 600$, ASPRS (1994)), HELIOS offers a broad range of applications. This includes the photogrammetric documentation of experimental sites as well as the verification of satellite-, and model-based estimates of sea ice and snow cover properties. Images taken simultaneously with other airborne observations provide a valuable tool to assess the accuracy of those measurements.
\end{abstract}

(C) 2010 Elsevier B.V. All rights reserved.

\section{Introduction}

The investigation of sea ice in Arctic regions by means of aerial photography goes back until the 1940s. By that time film-based photographs were the only remote sensing tool obtained on an operational level at high latitudes (Johannessen et al., 2005). Because practically all sea ice characteristics that are captured by the human eye can be determined on the basis of photographs as well, they were used to support navigation in the Northern Sea Routes and to gain fundamental insight into principals of ice dynamics and formation (Bushuyev et al., 1964; Hall and Rothrock, 1987; Tucker and Govon, 1981).

Today, the use of aerial photographs in the Arctic regions is very much limited, because since the 1980s, information on sea ice concentration and dynamics have been obtained, most reliably and over larger regions, from passive and active microwave sensors mounted on satellites or airborne platforms. In addition, the implementation of camera systems on board of aircrafts in Polar regions poses difficulties different to standard photogrammetric surveys: First, the transport of expensive photogrammetric systems demands extensive logistical efforts (Barnea et al., 2009). Second, most aircrafts that are used on Arctic surveys are helicopters without a

\footnotetext{
* Corresponding author. Tel.: + 4947148311753.

E-mail address: tkrumpen@awi.de (T. Krumpen).
}

designated shooting hole. Consequently, the heavy camera equipment needs to be placed outside the aircraft, which requires special protection and heating and limits the payload. Third, the camera operation can be complicated and time consuming.

The lack of aerial photography of sea ice was pointed out at the Climate and the Cryosphere ( $\mathrm{CliC}$ ) workshop on Arctic sea ice observations in Tromsø, 2009. The objectives of this workshop were to develop, standardize, and implement observation and measurement protocols for Arctic sea ice in coastal, seasonal, and perennial ice zones (Perovich and Gerland, 2009). It was proposed that there is a need for better and standardized documentation of airborne and ground-based sea ice measurements. Here, aerial photographs do provide a valuable contribution. Moreover, images can be used on field campaigns and expeditions to support planning and decision making (Steer et al., 2008) as well as to validate the accuracy of model results and airborne and satellite-based estimates of sea ice and snow cover properties (Krumpen et al., 2010; Leisti et al., 2009).

In this paper, we describe the development of a simple nadirlooking low-cost photogrammetric unit that is capable of filling the gap in experimental site documentation. The HELicopter-borne Ice Observation System (HELIOS) is designed such that it can be easily mounted on standard helicopters, withstands extreme conditions, operates autonomously and is simple to manufacture. Our aim is to test whether the system fulfils requirements on accuracy for the documentation of ground- and airborne surveys of sea ice. 
Below, we present the aerial unit, the image processing techniques and evaluate, based on data obtained during former expeditions, the precision of the system. Finally, we address the applicability of the system to validate models, satellites and other airborne measurements and discuss the use of HELIOS for mapping of sea ice characteristics like ice concentration and rafted ice.

\section{The aerial unit}

Photogrammetric mapping systems that are operated in remote areas are usually based on digital sensors (Petrie and Walker, 2007). The use of a digital system provides several advantages over filmbased cameras. For example, images are available immediately after the flight in an inherently computer-compatible format (Lillesand et al., 2004). Furthermore, the camera system can be adjusted or optimized easily during flight and data is stored on a reusable format. (Petrie and Walker, 2007) categorized the available digital frame camera systems into two major groups: Medium and small format systems that rely on consumer cameras and large format systems that are either based on a set of synchronized cameras in a rigid mount or on stepping frame cameras. The large format systems require a quite complicated integration of technical and mechanical elements, heavy stabilizer etc. (Barnea et al., 2009). These expensive platforms are designed for extensive (e.g. governmental) mapping projects of high accuracy and require substantial logistical efforts prior the survey. Small scale systems are much cheaper, easier to implement but of lower accuracy. The usage of these low-cost cameras for aerial photogrammetry has been discussed for a long period among the photogrammetric community (Barnea et al., 2009). It was shown by (Laebe and Foerster, 2004), (Petrie, 2006) and (Petrie and Walker, 2007) that less expensive consumer cameras, under certain, limited accuracy requirements, can be successfully implemented for photogrammetric purposes. The photogrammetric requirements in terms of accuracy and image quality for sea ice applications like the verification of satellite-, and model-based estimates are less demanding than conventional mapping standards (e.g. $\leq 0.5 \mathrm{~m}$ for a map scale of $1: 600$, ASPRS (1994)), since the image error is several magnitudes smaller than the spatial resolution of common model or satellite data products and because the ice changes rapidly due to its drift. Hence, the presented aerial unit is based on a low-cost consumer camera. Below, the system components and image processing techniques are described in detail.

Photogrammetric surveys in the Arctic environment require robust and energy efficient digital equipment. The HELIOS prototype is equipped with a rugged digital camera, the RICOH Caplio 500SE. The camera has an 8.3 megapixel sensor $(7.18 \times 5.32 \mathrm{~mm} \mathrm{CCD})$ and a wide angle $3 \times$ optical zoom lens, equivalent to a focal length of $28-84 \mathrm{~mm}$ on a $35 \mathrm{~mm}$ film. The image quality is high, with good saturation and contrast, and there is little to no evidence of corner softness and radial distortion. The camera is enclosed in a weatherproof plastic dome, which has been designed to withstand contact with water and extreme temperatures.

To compensate for pitch and roll of the aircraft, the nadir-looking camera is fitted on a two-axis gimbal (Fig. 1, left panel). The camera mount contains isolation bushings, insulating the sensor from vibration. The camera and gimbal were given additional weather protection by placing the unit inside a heated plastic enclosure $(41 \times 41 \times 30 \mathrm{~cm})$. The plastic enclosure is designed such that it fits to any standard helicopter skids (Fig. 1, right panel).

The RICOH camera is capable of writing GPS information into the image header. Geographic positions can be taken either from an internal or external GPS device. The internal GPS receiver consists of a $1 \mathrm{~Hz}$ SiRFStar III chip. As an external receiver we are using a $4 \mathrm{~Hz}$ Amtel/u-blox Antaris ${ }^{\circledR}$ chip placed outside the plastic enclosure to improve GPS reception. The position accuracy of the GPS receivers was tested by comparing measurements against a reference point of known location. Results are listed in Table 1.

Some mapping applications like photogrammetric surveys of experimental sites require proper flight track and acquisition point planning. This can be done using a geographical information system (GIS) or a flight management software. During flight, a GPS connected to the software shows the real-time position of the aircraft relative to the mission trail and the image acquisition points. When the acquisition point is reached, the camera is triggered manually by a laptop computer from inside the helicopter via a Bluetooth channel. If photographs are taken simultaneously with other airborne measurements, the system can be set such that it is released automatically with a predefined acquisition interval. Photographs taken are stored on the camera internal flash memory card. Under flight conditions $\left(-20^{\circ} \mathrm{C}\right)$, the operating-time of the battery driven system is approximately $4 \mathrm{~h}$.

\subsection{Image processing}

The fundamental task of aerial photography is to establish the geometric relationship between the image and the object as it existed at the time of the image event (Mikhail et al., 2001). Below, this process is referred to as georeferencing (Mather 1999). To locate and orient the image in the object coordinate system, the image center coordinates $\left(X_{0}, Y_{0}\right.$, and $\left.Z_{0}\right)$, the focal length, and the three orientation parameters, pitch, roll and yaw $(\omega, \varphi, \kappa)$, are needed (Kasser and Egels, 2002; Lillesand et al., 2004; Mikhail et al., 2001; Paine and Kiser, 2003). High precision photogrammetry also requires the determination of camera interior parameters in a laboratory. However, HELIOS images are predominantly used for the validation and/or documentation of models, satellites and other airborne data with a spatial resolution of several kilometers (e.g. models) to several tens of meters
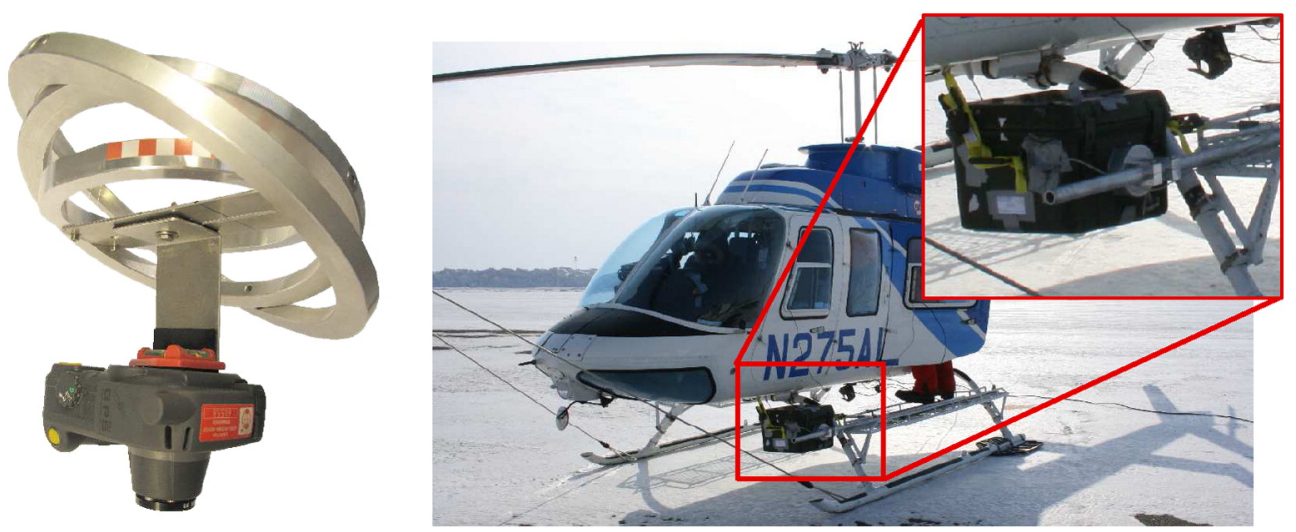

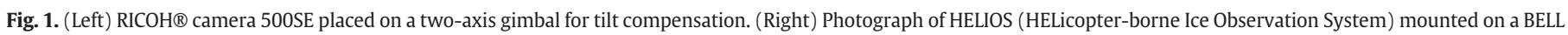
Helicopter. 
Table 1

Accuracy of GPS receivers tested by comparing the measurements against a reference point of known location.

\begin{tabular}{lll}
\hline GPS-chip & SiRFStar III & Amtel/u-blox Antaris \\
\hline Frequency & $1 \mathrm{~Hz}$ & $4 \mathrm{~Hz}$ \\
Mean distance from reference point & $\pm 4.4 \mathrm{~m}$ & $\pm 2.9 \mathrm{~m}$ \\
STDV & $\pm 7.2 \mathrm{~m}$ & $\pm 2.2 \mathrm{~m}$ \\
\hline
\end{tabular}

(e.g. TerraSAR-X Radar images). Thus, our requirements on accuracy are comparatively low. Because the interior camera calibration is a cost intensive procedure, the lens geometry is therefore neglected by assuming it to be flat-field.

$X_{0}, Y_{0}$, and $Z_{0}$ positions are taken from the camera internal GPS device. If using an external antenna, $X_{0}, Y_{0}$, and $Z_{0}$ need to be corrected for the displacement between the external GPS receiver and the camera position.

Pitch and roll of the aircraft are assumed to be fully compensated by the gimbal shown in Fig. 1, such that $\omega$ and $\varphi$ are set to $0 . \kappa$ is close to the flight direction and can be recorded by a digital compass or computed from a GPS receiver with two antennas placed at different positions. The measurement differences taken by the two antennas enable the determination of an accurate camera orientation relative to the flight direction. Note that this method requires additional processing and filtering (Barnea et al., 2009). To keep the system as simple as possible we therefore suggest to set $\kappa$ equivalent to the flight direction. Errors associated with this assumption are discussed below.

\subsection{Qualitative system evaluation}

During a Russian-German research expedition in winter 2009 (TRANSDRIFT XV), the accuracy of the camera system was tested by making 20 flights across a set of points of known location (ground control points, GCP). Flight speed was approximately $130 \mathrm{~km} / \mathrm{h}( \pm 15 \mathrm{~km} / \mathrm{h})$ and average flight height was around $85 \mathrm{~m}( \pm 7 \mathrm{~m})$. Image positions were taken 10 times with the external $4 \mathrm{~Hz}$ GPS receiver, and 10 times with the internal $1 \mathrm{~Hz}$ device. An image example is given in Fig. 2.

The mean displacement of image points from the GCP's is equivalent to the $X_{0}$ and $Y_{0}$ position error induced by the use of different GPS

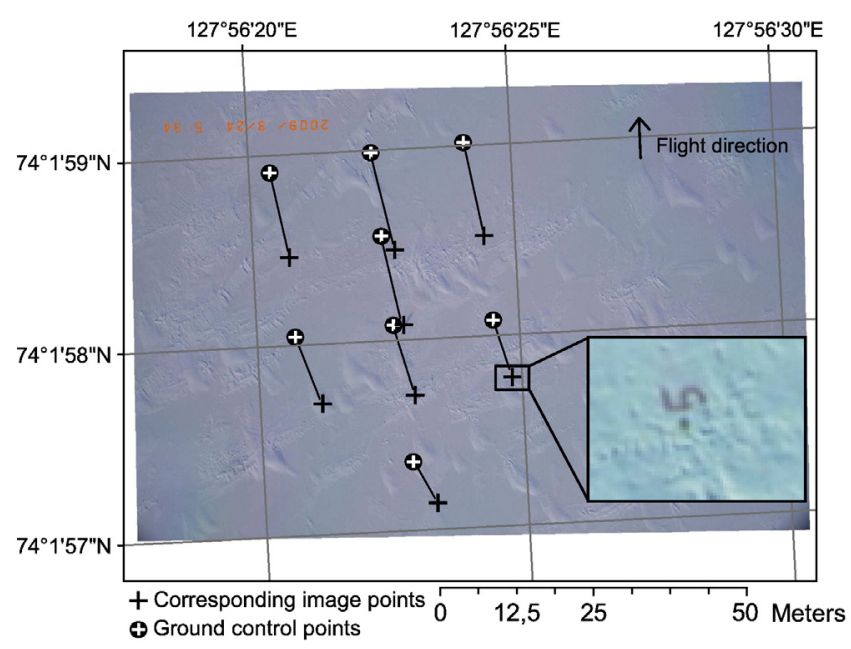

Fig. 2. Aerial photograph taken with HELIOS on March 24, 2009 (TD XV) using a $4 \mathrm{~Hz}$ GPS receiver. Image was obtained at $85 \mathrm{~m}$ flight height and covers a footprint of $109 \times 72 \mathrm{~m}$. The black crosses mark ground control points (GCP) of known locations on the fast ice (see enlargement). The white crosses show the locations of corresponding image points on the georeferenced image. Displacements between image points and GCP's give evidence of the accuracy of the system. Residuals should be of comparable size and point in random directions. A tendency in the displacement indicates the presence of a systematic error. Here, the image is tilted by an angle of $4^{\circ}$ against flight direction (pitch, $\omega$ ). The mean offset of image points from GCP's is $12 \mathrm{~m}$.

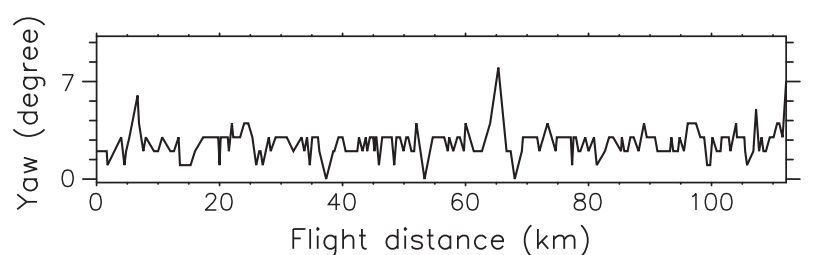

Fig. 3. Yaw $(\kappa)$ error resulting from the assumption that the camera is aligned with the flight path. The error is computed from the difference between true camera orientation recorded by a digital compass and flight direction computed from the GPS track. Data were obtained during a crosswind flight with a Russian MI-8 helicopter. The wind velocity at $2 \mathrm{~m}$ height was approximately $6 \mathrm{~m} / \mathrm{s}$.

frequencies. Image georeferencing based on a $1 \mathrm{~Hz}$ device results in a position mismatch of $\pm 60 \mathrm{~m}$. The use of a $4 \mathrm{~Hz}$ chip significantly improves the accuracy of $X_{0}$ and $Y_{0}$ determination by $75 \%$ to $\pm 15 \mathrm{~m}$.

Following (Mikhail et al., 2001), the pointing accuracy of the gimbal is calculated via the relative displacement between image points. We estimated the pointing accuracy in $\varphi$ direction to be within a range of $\pm 1^{\circ}$. Thus, the pointing accuracy of the gimbal in roll direction is satisfying. Unfortunately, the camera pitch against flight direction, induced by high helicopter accelerations, cannot be fully compensated by the suspension. Due to momentum, the precision of $\omega$ compensation is $\pm 5^{\circ}$. Note that the pointing accuracy of the gimbal could eventually be improved by adding some mass to the camera.

To keep the system as simple as possible, we suggest setting yaw equivalent to the flight direction. However, an aircraft in a crosswind can have several degrees of yaw. To quantify how close yaw $(\kappa)$ is to the flight direction, we compared the camera orientation recorded by a digital compass with flight direction estimates computed from the GPS track (Fig. 3). The data were obtained during a crosswind flight with a Russian MI-8 helicopter (TD XV). The wind velocity during flight was approximately $6 \mathrm{~m} / \mathrm{s}$. For the prescribed flight, the mean deviation between flight direction and camera orientation was $\pm 2^{\circ}$, which is acceptable. However, maximum values of $\pm 8^{\circ}$ can occur. Note that yaw angles might significantly differ under higher wind speeds and if using smaller helicopters.

An additional error arises from uncertainties in GPS camera height estimations. A comparison of the camera height as obtained from the $1 \mathrm{~Hz}$ GPS receiver with height information taken from a laser altimeter, gives evidence about the accuracy of the estimated camera height (Fig. 4). If the helicopter maintains flight height at $50 \mathrm{~m}$ $\left( \pm 10 \mathrm{~m}\right.$ ), the mean $Z_{0}$ positioning error is approximately $\pm 4 \mathrm{~m}$. Errors associated to larger flying height variations are unknown. Data were obtained to during a helicopter-borne, electromagnetic (HEM) ice thickness measurement flight (Haas et al., 2009) in April, 2008 in the Laptev Sea (TD XIII).

The error associated to the missing interior calibration of the camera is unknown. For example, lens distortion might result in radial displacements of imaged points from their theoretically correct positions. This is the most relevant interior aberration and can directly

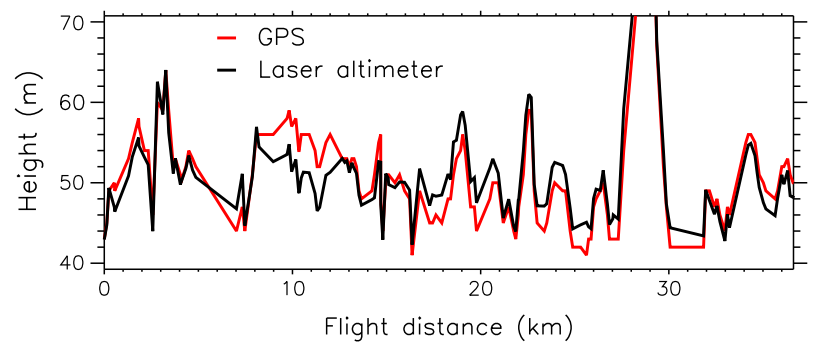

Fig. 4. Comparison of the camera height as obtained from the $1 \mathrm{~Hz}$ GPS receiver with height information taken from a laser altimeter. The difference gives evidence about the accuracy of the estimated GPS camera height. Data were obtained during a HEM flight in April, 2008 in the Laptev Sea (TD XIII). 


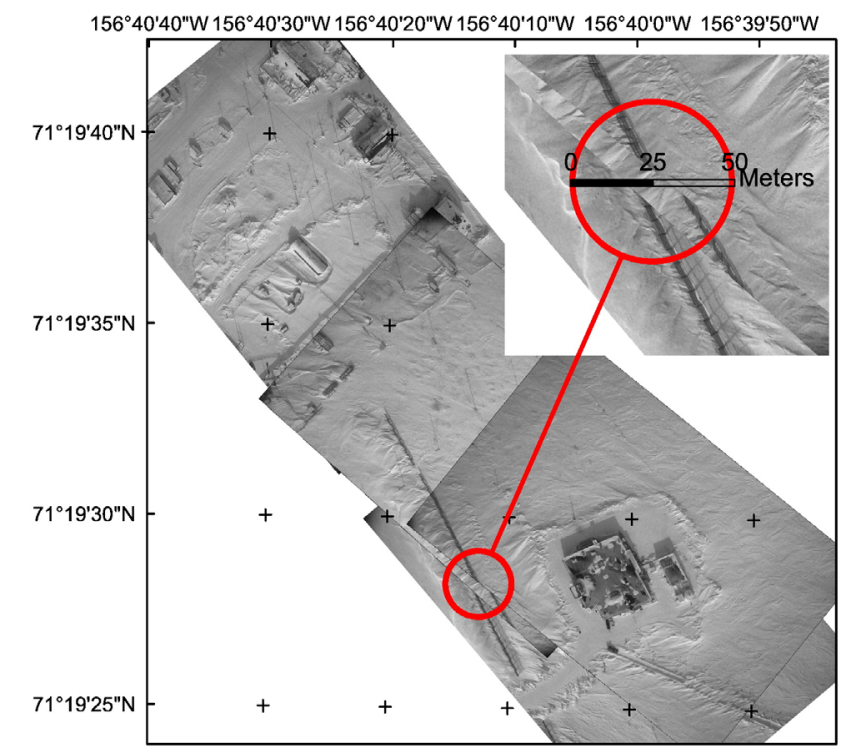

Fig. 5. Mosaic of aerial photographs, taken during a flight over Barrow, Alaska. 2 images were obtained with a $50 \%$ overlap heading towards North-West, and 2 photographs were taken without overlap heading towards South-East. Flight height was $250 \mathrm{~m}$ and flight speed was approximately $70 \mathrm{~km} / \mathrm{h}$. The mismatch between registered images gives evidence of the system accuracy (see enlargement).

affect the accuracy of the system. In particular, photogrammetric images that are taken at high altitudes might suffer from barrel and/or pincushion distortions. Here, software such as PTLense offers cheap and easy to use tools to correct for those lens-related issues. If images are taken at low flying altitudes, an interior calibration of the camera would not significantly improve the performance of the system, since aberrations related to the lens geometry are rather small compared to systematic errors introduced by the GPS and the gimbal.

\section{System applicability for various mapping projects}

Whether HELIOS can be used to document ground- and airborne sea ice surveys depends on the required accuracy of the mapping project.

An important application for aerial photography is the use of image information on sea ice distribution and characteristics to support ship navigation. For this application, requirements on geometric image accuracy are usually low and adequate results can be achieved by a hand-held camera, where the system time has been synchronized with a GPS. A trained observer can then separate multiyear and first year ice, estimate the rate of compression in sea ice fields and identify potential navigation passages. Here, the advantage of a system like HELIOS merely lies in its simple autonomous operation.

Furthermore, aerial photographs can be used for the verification of satellite-, and model-based estimates of sea ice and snow cover properties (Steer et al., 2008). For this application HELIOS is suitable, as the image error is several magnitudes smaller than the spatial resolution of common model or satellite data products.

In the past, images obtained by HELIOS were successfully applied in a number of studies. For example, information taken from aerial photographs were used by (Willmes et al., 2010) to contribute to the cross-validation of ice thickness estimates made by the Moderate Resolution Imaging Sensor (MODIS) and the Advanced Microwave Scanning Radiometer. They further aided interpretation of Environmental Satellite (ENVISAT) Synthetic Aperture Radar (SAR) imagery (Krumpen et al., 2010) and TerraSAR-X scenes (Busche et al., 2009). Moreover, photographs taken during a flight across a polynya in the Laptev Sea were employed for the calibration and validation of a polynya flux model (Krumpen et al., 2010), and to investigate the hydrographic response to ice formation (Dmitrenko et al., 2010).

If investigating potential anchoring grounds for ships and landing strips for planes, mapping sea ice characteristics in the vicinity of experimental sites, or surveying the experimental site itself, a much higher accuracy (of the order of several meters) is needed. It was shown that this level of accuracy is achieved by the camera system, if a GPS with a frequency of more than $4 \mathrm{~Hz}$ is used and flight conditions are relatively stable. Fig. 5 shows a mosaic of aerial photographs taken with HELIOS over an experimental site of the Ocean Atmosphere Sea Ice Snowpack (OASIS 2009) campaign in Barrow, Alaska. According to the mismatch between registered images, the accuracy of the georeferenced photographs is around $\pm 8 \mathrm{~m}$. Theoretically, the precision of the image localization and orientation can be further improved by the use of $10 \mathrm{~Hz}$ GPS, a GPS reference station and/or a reduction in flight speed.

Moreover, HELIOS was applied to document a number of other airborne observations. For instance, images taken simultaneously to sea ice surface temperature records made by a pyrometer were used to obtain information about the spatial distribution of open water patches, compression such as rafting or ridging, and the presence of frost flowers or snow on top of the ice. Some parameters such as ice concentration, ice type, compression and floe size can be extracted automatically from digital 8-bit, RGB (red, green, blue) images. This is done by band thresholding, simple classification methods or convolution filters. For an in-depth description and discussion of these processing techniques we refer to (Weissling et al., 2009).

Fig. 6 shows a series of aerial photographs collected during the pyrometer flight across an active polynya on March 27, 2009. To

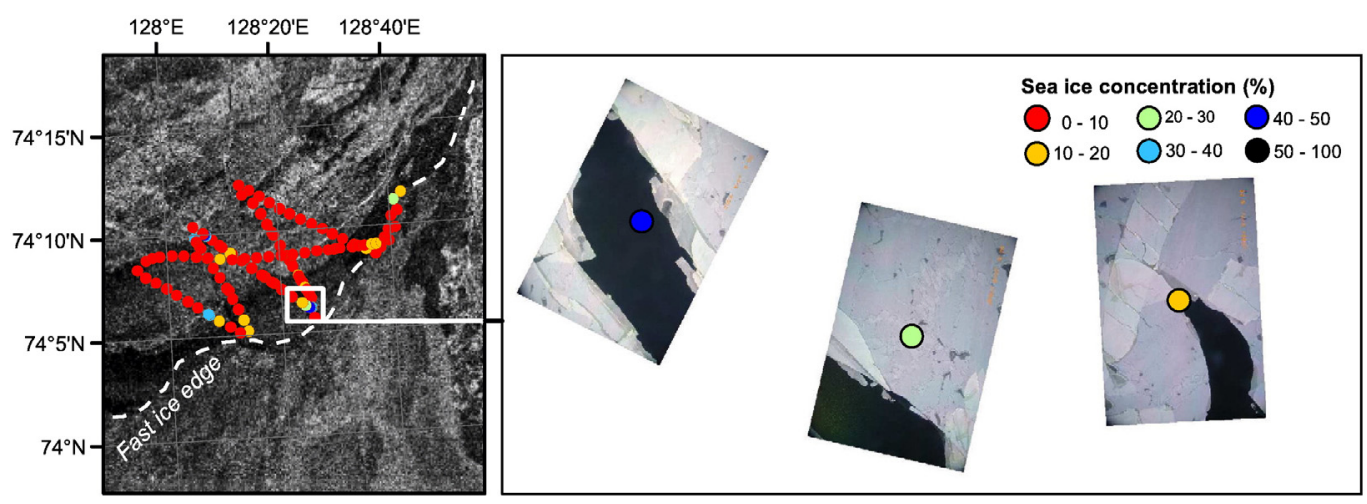

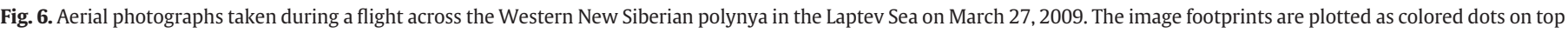

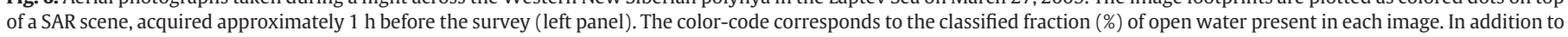

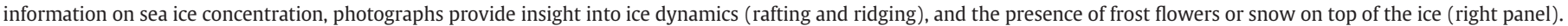




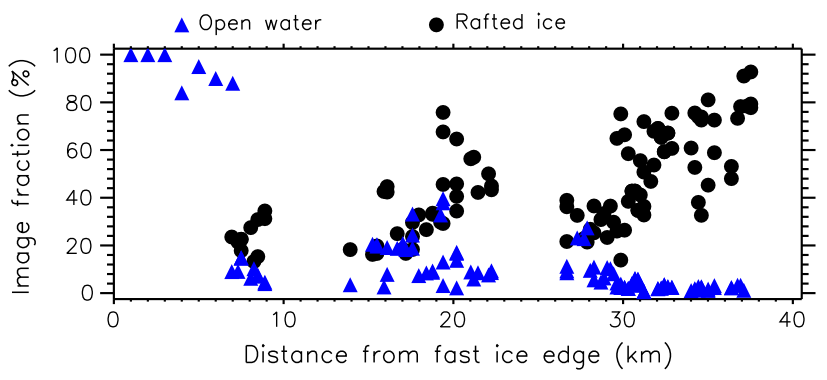

Fig. 7. Image segmentation results of an aerial photo survey performed across a polynya in the Laptev Sea on April 29, 2008 at 4 UTC: Blue triangles represent the open water fraction extracted from individual aerial photos with distance from fast ice edge. The black circles show the fraction of rafted thin ice.

determine the fractions of open water in each photo, a band thresholding method is used. Note that photographs taken over water or ice without snow cover often show mirror-like reflections of light. These specular effects are caused by the relationship that exists among solar elevation, azimuth angle and camera orientation (Lillesand et al., 2004). Thus, a radiometric image enhancement needs to be done prior to segmentation. Cross- and along track variation in illumination are corrected by fitting a polynomial function of second order to the cross- and along track means.

Likewise, spatial information on rafted and unrafted ice in polynyas can be obtained from the imagery. Fig. 8 shows a single image taken simultaneously with a HEM flight on April 29, 2008 across a polynya and segmentation results. The segmentation thresholds were set such that a digital number (DN) below 60 identifies open water, while a DN above 120 comprises rafting. Classes are then segmented into areas of connected pixels. The minimum area of a potential open water or rafting zone is $0.2 \mathrm{~m}^{2}$. To separate between rafted ice and unrafted ice a minimum contrast between features is needed. Flat sun angles, clouds or the presence of snow or frost flowers on thin ice make it difficult or impossible to distinguish between rafted and unrafted ice using a simple threshold value. Another limiting factor for ice feature separation is the ice thickness. Unrafted ice thicker than $30 \mathrm{~cm}$ has a brightness value similar to rafted ice. Thus, a separation works well only for unrafted ice thinner than $30 \mathrm{~cm}$. Fig. 7 presents fractions of classified open water and rafted ice in individual aerial photos taken during the same flight with distance from the polynya edge. At the time of the aerial survey, the observed polynya open water width was $7 \mathrm{~km}$. Thin ice covered an area of 7 to $38 \mathrm{~km}$ on the downwind side of the polynya. Data gaps between $9-14 \mathrm{~km}$ and $23-26 \mathrm{~km}$ result from HEM instrument calibration (Haas et al., 2009).

Some airborne instruments, like HEM ice thickness sensors, require flying altitudes below $50 \mathrm{~m}$. Hence, the image footprint becomes relatively small and converges towards the accuracy of the georeferenced image. As a consequence, features measured by the instrument may be outside the image frame. Nevertheless, photographs can be used to assess the relative accuracy of the low-level airborne measurements.

\subsection{Conclusion}

In this paper we present the prototype of a photogrammetric system that can be used for the mapping of sea ice in high latitudes. Compared to standard high-end photogrammetric mapping systems, HELIOS is designed for simplicity and flexibility. It withstands low temperatures and contact with water, is of low weight and cost, operates autonomously and fits to any standard helicopter skid. Because the system is based on a digital camera, images are available immediately after the survey.

The performance of the system was tested by means of accuracy analysis and case studies. It was found that use of an external high frequency GPS receiver ( $4 \mathrm{~Hz}$ ) significantly improves the accuracy of the georeferenced image by as much as $45 \mathrm{~m}$ compared to the camera internal $1 \mathrm{~Hz}$ device. The accuracy of GPS camera height estimation is around $\pm 4 \mathrm{~m}$. The pointing accuracy of the two-axis gimbal in roll direction is satisfying, while camera pitch against flight direction cannot be fully compensated by the suspension. For simplicity, yaw is set equivalent to the flight direction. This assumption is likely to introduce an additional error during crosswind flights.

Overall, we found HELIOS to be sufficient for the documentation of various ground- and airborne sea ice surveillances. This applies to standardized and regular documentation of sea ice surface properties as well as the verification of satellite-, and model-based estimates of sea ice and snow cover properties. Nevertheless, for photogrammetric mapping surveys requiring an accuracy of the order of several meters, the use of a high frequency GPS is mandatory and flight conditions need to be relatively stable. At low camera heights the image footprint becomes relatively small and converges towards the accuracy of the
Geocoded image

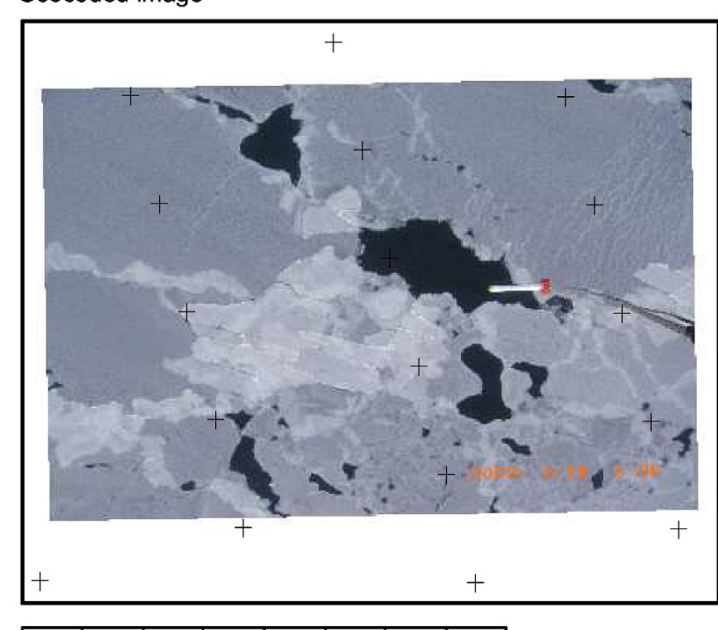

Classification result

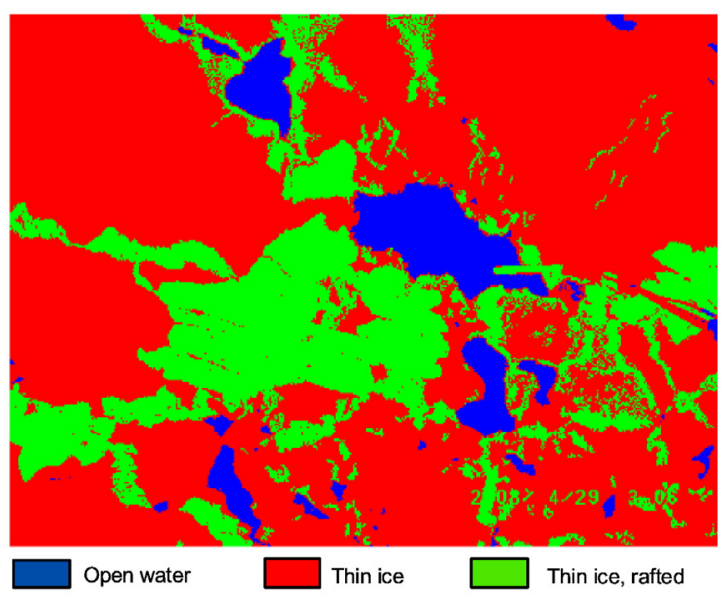

0

25

50 Meters

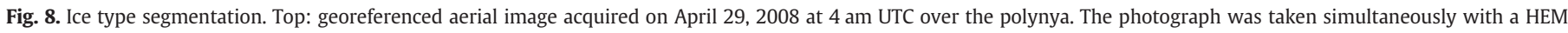

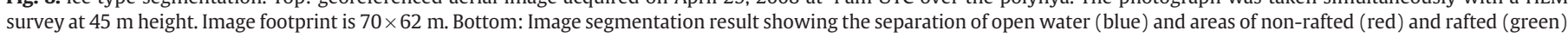
ice. 
georeferenced image. This in turn limits the applicability of HELIOS for the documentation of airborne measurements that require low flying altitudes.

\section{Acknowledgements}

This work was part of the German-Russian cooperation 'System Laptev Sea' funded by the BMBF under grant 03G0639A and the Alfred-Wegener Institute. The authors kindly acknowledge exchange and helping hands during field campaigns from other project members and Russian colleagues. ENVISAT Satellite data were obtained through ESA Project EO-500 "Formation, transport and distribution of sediment-laden sea ice in the Arctic Shelf seas".

\section{References}

ASPRS, 1994. Photogrammetric accuracy standards and classifications. ASPRS Standards EM 1110-1-1000. American Society for Photogrammetry and Remote Sensing. Maryland, US.

Barnea, S., Shragai, Z., Suliman, Z., Yalon, D., ad Shechter, M., 2009. Mapping remote areas with a portable high-accuracy photogrammetric system. Surveyors Key Role in Accelerated Development. FIG Working Week, Eilat, Israel.

Busche, T., Hajnsek, I., Krumpen, T., Rabenstein, L., Hoelemann, J., Haas, C., Willmes, S. 2009. Investigating coastal polynya thin sea ice state in the Laptev Sea using TerraSAR-X Dual-Pol stripmap data. IGARSS 2009 Conference Proceedings, IEEE.

Bushuyev, A.V., Volkov, N.A., S.L.V., 1964. Physical-geographical Characteristics of Ice Cover of the Arctic Basin and Marginal Seas. AARI Archives.

Dmitrenko, I.A., Wegner, C., Kassens, H., Kirillov, S.A., Krumpen, T., Heinemann, G., Helbig, A., Schroeder, D., Hoelemann, J.A., Klagge, T., Tyshko, K.P., Busche, T., 2010 Observations of supercooling and frazil ice formation in the Laptev Sea coastal polynya. Journal of Geophysical Research 115.

Haas, C., Lobach, J., Hendricks, S., Rabenstein, L., Pfaffling, A., 2009. Helicopter-borne measurements of sea ice thickness, using a small and lightweight, digital EM system. Journal of Applied Geophysics 67, 234-241.
Hall, R.T., Rothrock, D.A., 1987. Photogrammetric observations of the lateral melt of sea ice floes. Journal of Geophysical Research 92, 7045-7048.

Johannessen, O.M., Yu, V., Alexandrov, I., Frolov, Y., Sandven, S., Miles, M., Bobylev, L.P., Pettersson, L.H., Smirnov, V.G., Mironov, E.U., 2005. Remote Sensing of Sea Ice in the Northern Sea Route: Studies and Applications. Springer Praxis Books.

Kasser, M., Egels, Y., 2002. Digital Photogrammetry. Taylor and Francis, London.

Krumpen, T., Willmes, S., Morales Maqueda, M.A., Gerdes, R., Haas, C., Hoelemann, J., Schroeder, D., 2010. Verification of a polynya flux model by means of thermal infrared satellite observations. Annals of Glaciology 52, 57.

Laebe, T., Foerster, W., 2004. Geometric Stability of Low-Cost Digital Consumer Cameras., in: International Archives of ISPRS. ISPRS Congress, Istanbul. pp. 528-535.

Leisti, H.K.R., Heiler, I., Eriksson, P., Haapala, J., 2009. A method for observing compression in sea ice fields using IceCam. Cold Region Science and Technology $59,65-77$.

Lillesand, T., Kiefer, R., Chipman, J., 2004. Remote Sensing and Image Interpretation. John Wiley and Sons, New York.

Mikhail, E., Bethel, J., Mcglone, J., 2001. Introduction to Modern Photogrammetry. John Wiley \& Sons, New York.

Paine, D.P., Kiser, J.D., 2003. Aerial Photography and Image Interpretation. WileyBlackwell, New York, US.

Perovich, D.K., Gerland, S., 2009. Developing and implementing protocols for Arctic Sea ice observations. EOS 90, 169-170.

Petrie, G., 2006. IGI's airborne systems-an expanded product range! Geolnformativs 9, $36-41$

Petrie, G., Walker, A.S., 2007. Airborne digital imaging technology: a new overview. The Photogrammetric Record 22, 203-225.

Steer, A., Worby, A., Heil, P., 2008. Observed changes in sea-ice floe size distribution during early summer in the western Weddell Sea. Deep-Sea Research 55, 933-942.

Tucker, W.B., Govon, J.W., 1981. Morphological investigations of first-year sea ice pressure ridge sails. Cold Region Science and Technology 5, 1-12.

Weissling, B., Ackley, S., Wagner, P., Xie, H., 2009. EISCAM-digital image acquisition and processing for sea ice parameters from ships. Cold Region Science and Technology 57, 49-60.

Willmes, S., Krumpen, T., Adams, S., Rabenstein, L., Haas, C., Hoelemann, J., Hendricks, S., 2010. Cross-validation of polynya monitoring methods from multi-sensor satellite and airborne data: a case study from the Laptev Sea. Canadian Journal of Remote Sensing 36. 